\title{
Papel do genoma e do microbioma na patogenia e abordagem terapêutica da asma
}

\author{
Role of the genome and microbiome in the pathogenesis and treatment of asthma
}

\section{Hisbello da Silva Campos ${ }^{1}$}

\section{RESUMO}

Asma é uma denominação única para um conjunto de disfunções respiratórias que se expressam, clinicamente, por episódios repetidos, com intensidade variável de dispneia, sibilos, tosse e opressão torácica. A variação entre suas formas clínicas é resultante da participação e interação entre fatores genéticos, microbiômicos e ambientais. O progresso na área médica, ao incorporar novos recursos tecnológicos da biociência e bioinformática, vem desvendando a intimidade dos processos genéticos e moleculares envolvidos nos diferentes mecanismos patogênicos presentes na asma. Isso vem levando à identificação de novos alvos terapêuticos e à pesquisa de novos agentes medicamentosos. Ao mesmo tempo, a perspectiva de inserção paulatina desses recursos no cotidiano médico tem promovido mudanças na prática médica, que vem adotando os princípios da medicina de precisão. Possivelmente, estas mudanças melhorarão o horizonte dos asmáticos, uma população ainda desprovida de instrumentos terapêuticos totalmente efetivos.

Descritores: Asma, genética, microbiota, medicina de precisão.

\section{Introdução}

$\mathrm{Na}$ medida em que vão ficando mais claros os diversos mecanismos envolvidos na multifatoriedade, heterogeneidade e diversidades nas respostas terapêuticas na asma e como eles estão imbricados, vamos compreendendo que a asma é o produto de uma interação complexa e variável entre fatores genéticos, ambientais e o microbioma. Fundamentalmente, a asma é uma alteração respiratória resultante do comportamento anormal das células constituintes e funcionais do trato respiratório determinado por alterações genômicas, que tanto podem ser herdadas dos

\section{ABSTRACT}

Asthma is a unique designation for a set of respiratory dysfunctions clinically expressed by repeated episodes of varying intensity of dyspnea, wheezing, cough, and chest oppression. The variation between its clinical forms is the result of the participation and interaction between genetic, microbiomic, and environmental factors. Progress in the medical field, with incorporation of new technological resources from bioscience and bioinformatics, has been unveiling the intimacy of genetic and molecular processes involved in the different pathogenic mechanisms present in asthma. This has led to the identification of new therapeutic targets and the search for new therapeutic agents. At the same time, the perspective of gradual insertion of these resources in daily medical activities has been promoting changes in medical practice, which has been adopting the principles of precision medicine. Possibly, these changes will provide a better future for asthmatic patients, a population still devoid of fully effective therapeutic instruments.

Keywords: Asthma, genetics, microbiota, precision medicine.

pais como serem produto de influências epigenéticas e/ou de disbioses no microbioma ${ }^{1}$.

Atualmente, em algumas situações clínicas, os alvos terapêuticos são definidos no nível molecular, enquanto a prática médica vem usando e incorporando novos guias e conceitos, como "Ciências ômicas" e "Medicina de precisão", agregando novas estratégias e novos personagens, como "Farmacogenômica" e "Nanotecnologia"2,3. Certamente, esses avanços modificarão a abordagem da asma, principalmente na diferenciação precisa entre as suas apresenta-

1. Instituto Fernandes Figueira, Fiocruz, Alergia e Imunologia clínica - Rio de Janeiro, RJ, Brasil. 
ções clínicas e no tratamento, que deixará de ser genérico - anti-inflamatórios (corticosteroides) e broncodilatadores - e passará a buscar o retorno da célula ao seu comportamento normal.

Nesse texto, com base numa revisão bibliográfica na plataforma PubMed em que foi usada a associação do termo "asma" aos termos "mecanismos patogênicos", "genética", microbioma", "ciências ômicas", "microRNA", "sequenciamento genômico", "biomarcador", "nanotecnologia", "nanoterapia", "farmacogenética" e "farmacogenoma", foram incluídos apenas artigos de língua inglesa publicados nos últimos 15 anos. O objetivo foi o de fazer uma revisão narrativa dos novos conhecimentos sobre o valor dos fatores genéticos e do microbioma na asma. São comentadas, também, as novas perspectivas terapêuticas potenciais.

\section{Classificando o asmático}

A categorização do doente é o passo inicial na decisão terapêutica. No caso da asma, a classificação fenotípica é a usada tradicionalmente. Porém, com a incorporação de novos conhecimentos nos mecanismos patogênicos, surgiu uma nova proposta de classificação: segundo o endotipo. Esse designa a forma clínica segundo o mecanismo patogenético determinante da disfunção ${ }^{4}$. Inegavelmente, essa seria a forma ideal de classificar uma doença, já que apontaria diretamente para a causa do problema. Entretanto, assim como ocorre com os fenótipos, os endotipos estão sujeitos a variações ao longo do tempo e podem se sobrepor uns aos outros. Outro ponto importante diz respeito ao fato de que, mesmo que o endotipo esteja associado a um único mecanismo molecular, a maior parte deles compartilha processos etiológicos e patogênicos através de interações lineares dinâmicas, que podem não estar presentes em todos os pacientes ou num mesmo paciente todo o tempo. Na prática, isso é refletido pela dinâmica nas formas clínicas com as quais a asma se apresenta, indicando que as abordagens terapêuticas também deveriam ser dinâmicas. O ideal seria dispormos de biomarcadores que indicassem com precisão o(s) endotipo(s) em atividade em cada momento, apontando os alvos terapêuticos ${ }^{5}$.

A designação "Complexo endotípico dinâmico" resume a perspectiva atual com que a asma é vista: um processo dinâmico no qual diferentes mecanismos moleculares patogênicos incluem subendotipos, que tanto podem se alternar como se somar ${ }^{6}$. Assim, no complexo endotípico tipo 2, que compreende diferentes subendotipos longitudinais ou concomitantes, teríamos o envolvimento de células Th2, células linfoides inatas tipo 2 (ILC2), subcategorias tipo 2 de células $B$, subcategorias de células $T$ natural killer (NKT), eosinófilos, mastócitos, basófilos, e suas citocinas (IL-4, IL-5, IL-13, p. ex.), anticorpos da classe IgE, moléculas de superfície (CRTH2, p. ex.) e mediadores solúveis, como a histamina.

A patogenia da asma é um processo complexo resultante da interação de múltiplos genes, moléculas, microrganismos, fatores ambientais, estilo de vida, dieta, entre outros. Nesse cenário, busca-se identificar biomarcadores capazes de unir fenótipo e endotipo, indicando o(s) alvo(s) terapêutico(s) ${ }^{1}$ e selecionando o tratamento apropriado em cada momento. Atualmente, não dispomos de biomarcadores que indiquem, com precisão, o endotipo específico e, consequentemente, 0 alvo do tratamento ${ }^{7}$. Algumas linhas de pesquisa buscam identificar biomarcadores precisos e factíveis na realidade dos sistemas de saúde, que permitam apontar o endotipo responsável em cada momento e, por conseguinte, o plano terapêutico mais apropriado. Dado o número exponencial de dados a serem avaliados nesses estudos, e a diversidade e mobilidade dos perfis dos asmáticos, as amostras e grupos controle têm que ser numerosos, tornando-os ainda mais complexos e dispendiosos.

\section{Aspectos genéticos da asma}

A hereditariedade da asma é um fato ${ }^{8}$. A herança do fenótipo asmático pode ser resultado de muitos mecanismos, que são divididos em dois grupos: os que alteram a sequência do DNA e os que não alteram. Esses últimos, que incluem um conjunto de modificações que afetam o genoma sem alterar a sequência intrínseca do DNA constituem a epigenética. Essas modificações, mediadas por enzimas, incluem a metilação do DNA, mudanças na ligação do DNA às proteínas histonas e na expressão de RNA não-codificante (como o microRNA - miRNA). A regulação epigenética da expressão genética $e$ produção proteica é um mecanismo que contribui para o desenvolvimento e adaptação às alterações do meio celular subsequentes às mudanças ambientais. Estudos do tipo GWAS (Genome Wide Association Studies), feitos em grande escala com a finalidade de avaliar as modificações que alteram a sequência do DNA, identificaram um número reduzido de mudanças genéticas associadas à asma, não necessariamente 
causais; além disso, muito significativas numa escala populacional, mas não preditivas no nível individual. ${ }^{9}$ Com a impossibilidade de os GWAS explicarem a grande proporção de variantes fenotípicas da asma $^{10}$, e uma vez estabelecida a importância do componente ambiental na patogenia da asma ${ }^{11-13}$, os mecanismos epigenéticos passaram a ser objeto de estudos visando compreender como interfeririam na susceptibilidade e gravidade da asma, gerando os múltiplos fenótipos, que passam a ser herdáveis ${ }^{14}$. Passou-se a estudar, também, se eles poderiam ser alvos terapêuticos. Entretanto, ainda não é possível dizer se as mudanças epigenéticas identificadas são causa ou resultado da asma ${ }^{15-17}$. Como exemplo da complexidade dos estudos para solucionar essa questão, deve-se lembrar que cada tipo celular tem um epigenoma distinto, tornando importante investigar mudanças com a doença em cada tipo celular isoladamente $\mathrm{e}$, posteriormente, usar os instrumentos da bioinformática para agregar os dados ${ }^{18}$. Outro exemplo das dificuldades enfrentadas nessa linha de estudo é o grande espectro de ação das enzimas responsáveis pelas modificações epigenéticas, todas com múltiplos alvos, tanto na asma como em outras doenças. $\mathrm{O}$ aspecto dinâmico das modificações epigenéticas que, diferentemente das mudanças no DNA, podem ser revertidas, representa a possibilidade de reversão de pelo menos parte dos mecanismos patogênicos envolvidos na asma. Isso vem direcionando o desenvolvimento de novos agentes terapêuticos cujos alvos são representados por genes e áreas específicas do genoma ${ }^{19}$.

O aprimoramento das técnicas de sequenciamento do DNA vem agregando informações importantes para a compreensão dos perfis de risco para adoecimento e dos mecanismos patogênicos. Cada genoma humano contém de 3 a 5 milhões de variações genéticas quando comparado com a sequência de referência. A maioria dessas variações não está ligada a processos doentios. Na suspeita de associação de uma variação qualquer a um mecanismo patogênico, devem ser investigados o fenótipo, a estrutura familiar e o padrão de herança hereditária. Nesse tipo de análise, a acurácia é vital, já que não apenas o indivíduo, mas também seus familiares e futuras gerações serão afetados se for feito um diagnóstico inadequado. As novas tecnologias de sequenciamento do DNA - next generation sequencing (NGS) - estão revolucionando a medicina genômica. Basicamente, as plataformas NGS identificam o sequenciamento dos nucleotíde- os, promovendo a quebra do DNA em milhões de pequenos fragmentos que são analisados através da bioinformática e "realinhados". A seguir, toda a sequência é comparada com o genoma humano de referência. Através de NGS, todo o genoma pode ser sequenciado ou apenas as áreas de interesse, incluindo todos os 22.000 genes codificantes ou apenas os genes individuais ${ }^{20}$.

Duas grandes metanálises, uma em população europeia (GABRIEL) ${ }^{21}$ e outra em população norteamericana (EVE) ${ }^{22}$ identificaram as mesmas quatro regiões cromossômicas como associadas à susceptibilidade para asma em pessoas de diferentes bases étnicas ${ }^{23-25}$. Estudos GWAS recentes trouxeram informações interessantes, tais como:

- a asma de início na infância está associada com locais cromossômicos diferentes daqueles ligados a outras formas de asma e de doença alérgica;

- a asma de início na idade adulta e a asma moderada a grave estão associadas a menor número de genes, os quais, em sua maioria, são parte de um subgrupo dos genes associados à asma de início na infância;

- há sobreposição genética significativa na asma (particularmente a de início na infância) e em doenças alérgicas, envolvendo genes associados à função biológica de barreira e ao HLA (genes mais frequentemente associados aos dois grupos de doenças ${ }^{26}$.

A busca de preditores genômicos da asma grave é complexa. Os principais obstáculos recaem na limitação fenotípica usada por clínicos para agrupar grandes amostras, na necessidade de muitos grupos (compreendendo diferentes gravidades) para comparação, a variabilidade sintomática intraindividual e a necessidade de inclusão de fenótipos intermediários, como medidas da função pulmonar, hiperresponsividade brônquica (HRB), biomarcadores e graus de resposta ao tratamento.

Análises farmacogenéticas, apontando genes ou regiões cromossômicas associadas às respostas aos diferentes fármacos podem ajudar na identificação de preditores genômicos das diferentes formas de asma ${ }^{27}$. Indiscutivelmente, há participação genética na resposta aos glicocorticoides inaláveis ${ }^{28-30}$. O mesmo vale para as respostas aos beta-2 agonistas ${ }^{31-33}$ e, provavelmente, para os demais medicamentos usados na asma ${ }^{21}$. 


\section{Microbioma modulando a asma}

O corpo humano evoluiu oferecendo pouso para trilhões de micróbios que interagem com nossa fisiologia. Desequilíbrios nessa população de microrganismos (disbiose) estão associados a inúmeras disfunções, como doença do intestino irritável, esclerose múltipla, diabetes, autismo, câncer, alergia e asma, entre outras ${ }^{34}$. Regularmente, essa população de microrganismos apresenta grande variabilidade interindividual, mesmo na ausência de doença, o que dificulta a definição de espécies responsáveis pelas diversas doenças associadas às disbioses ${ }^{35}$.

Uma determinada comunidade de microrganismos num ambiente do corpo (pele, intestino, pulmão, p.ex.) é denominada microbiota. Quando nos referimos às funções que ela desempenha nesse ambiente (absorção de nutrientes, proteção contra patógenos, modulação genética, entre outras), estamos falando do microbioma. O microbioma é um ecossistema composto, majoritariamente, por comensais e mutualistas, capaz de interagir com a maior parte dos nossos órgãos. Ele pode variar marcadamente entre as pessoas e é modulado pelos hábitos alimentares, estilo de vida, gênero, fisiologia, níveis hormonais, e outros fatores. Sua composição e aspectos funcionais variam durante os períodos da vida. O microbioma humano é uma fonte de diversidade genética, um "modificador" de doenças e um componente essencial da imunidade, bem como uma entidade funcional que metaboliza e modula as interações medicamentosas. A simbiose biológica entre o microbioma e seu hospedeiro influenciam a fisiologia humana, o desenvolvimento dos sistemas neural e imune, entre outros, tendo efeitos sobre a variação humana e a individualidade. Sem essa simbiose, não haveria vida, como nós a conhecemos. Estudos GWAS identificaram variações genéticas associadas ao microbioma, ligando-o a diferentes fenótipos e associando-o a doenças. Mecanismos regulatórios modulam a interação à composição do microbioma e à variação genética do hospedeiro ${ }^{36}$. Foram identificados efeitos funcionais de ligantes estruturais chave e de metabólitos da microbiota pulmonar sobre a imunidade inata e adaptativa ${ }^{37}$. Esses fatos fazem de determinados aspectos da microbiota preditores potenciais do risco de doenças ${ }^{38}$. Parte dos componentes do microbioma humano tem o potencial de modular diretamente a expressão genética do nosso corpo e os processos enzimáticos usados na metabolização dos fármacos administrados (citocromo P450s, desidrogenases, carboxilesterases), fazendo com que ele seja con- siderado no desenvolvimento de novos fármacos e definição de doses ${ }^{39}$.

Estudos em humanos demonstraram associações entre a presença de determinadas bactérias no trato respiratório no início da vida e risco de sensibilização alérgica e asma posteriormente. Outros, revelam que algumas alterações na microbiota intestinal de neonatos parecem preceder o desenvolvimento da asma $^{40,41}$. Progressos recentes nas técnicas de sequenciamento molecular e de bioinformática vêm possibilitando a caracterização detalhada da população bacteriana residente no corpo, gerando evidências de que o tamanho e a diversidade da microbiota pulmonar são maiores em asmáticos do que em sadios ${ }^{42}$, e que ela varia, tanto em diversidade como em composição, de acordo com a gravidade e o fenótipo da asma $^{43}$. Em portadores de asma leve, a diversidade bacteriana está inversamente associada ao grau de $\mathrm{HRB}^{28} \mathrm{e}$, na medida em que ela se torna mais grave, há menor diversidade bacteriana associada ao aumento da obstrução ao fluxo aéreo ${ }^{44}$. Foi demonstrado que variações na microbiota pulmonar em resposta a tratamento profilático com macrolídeos interferem com o grau de HRB e de parâmetros de inflamação das vias aéreas ${ }^{45}$. A microbiota em amostras de escarro de asmáticos neutrofílicos mal controlados tem menos diversidade que a de asmáticos não neutrofíli$\cos ^{46}$. Embora ainda haja divergências de resultados, há relatos de disbioses no intestino de neonatos, com proporção reduzida de E. coli ${ }^{47}$ e Bifidobacteria ${ }^{48}$, e aumentada de Clostridia ${ }^{49}$. Proporção reduzida de Bifidobacteria também foi descrita em asmáticos adultos, quando comparados a não asmáticos ${ }^{50}$.

\section{A evolução da prática médica e perspectivas para o asmático}

Tradicionalmente, a prática médica era fundamentada em sintomas. A partir deles, a história clínica buscava dados de exposição a fatores patogênicos e informações sobre a evolução dos sintomas. Com esse conjunto de dados, formulavam-se hipóteses diagnósticas e selecionava(m)-se o(s) exame(s) complementar(es) apropriado(os) para confirmá-las. Era uma prática apoiada, em grande parte, no "saber médico e na experiência" de profissionais respeitados. A esses médicos "peritos" eram solicitados padronizações terapêuticas, diretrizes e consensos, que eram vistos como instrumentos para democratizar o saber médico. Os resultados dessas intervenções padronizadas tanto podiam ser favoráveis, como ausentes 
ou adversos. Na década de 90 , a evolução surgiu com um movimento que teve o nome de "Medicina Baseada em Evidências (MBE)", que pregava maior objetividade na decisão médica. Surgem as metanálises que providenciavam revisões sistematizadas de evidências baseadas em pesquisas comparativas. Entretanto, mesmo a MBE tem limitações importantes decorrentes das fronteiras entre as aplicações dos resultados de ensaios clínicos/revisões sistemáticas e às circunstâncias do paciente individual. Tanto a Medicina Baseada em Sintomas (MBS) quanto a baseada em evidências focam sintomas, mecanismos patogênicos e respostas terapêuticas, deixando de lado a importância de certas nuances do indivíduo doente. Dessa forma, determinados aspectos genômicos, estilo de vida, exposições ambientais, dieta habitual, entre outros, não são incorporados na investigação diagnóstica ou na decisão terapêutica. Esse cenário pode mudar com a avaliação do paciente por diferentes perspectivas e os mecanismos de adoecimento estudados no nível molecular. Nessa perspectiva, denominada Medicina de Precisão (MP), reconhece-se e valoriza-se o fato de cada pessoa possuir aspectos e características únicas nos níveis genômico, molecular, fisiológico, comportamental e nas exposições ambientais. Com base nessa perspectiva, e com a inclusão das tecnologias emergentes na área médica - sequenciamento de DNA, plataformas ômicas, técnicas de produção e de análise de imagens, aplicativos para monitorar dados da saúde - prevê-se uma mudança benéfica na maneira com a qual o processo saúde-doença é visto. As novas tecnologias permitem constatar a grande variabilidade interindividual no que se refere aos efeitos dos fatores e mecanismos contribuintes para os processos de adoecimento. Na MP, essa variação é considerada na decisão da melhor terapia, da melhor monitoração e prevenção em cada situação patológica. Ou seja, a abordagem é feita sob medida, personalizada para o perfil único de cada pessoa, no que se refere ao seu padrão genômico, bioquímico, fisiológico, psicológico, ambiental e comportamental.

A MP é um processo que incorpora mudanças fundamentais. Mudanças na formação dos profissionais de saúde, que além de dominar áreas básicas, como anatomia, fisiologia, farmacologia e semiologia, por exemplo, devem estar aptos para utilizar recursos sofisticados da informática e inteligência artificial. $\mathrm{Na}$ MP, a abordagem sistemática incluirá informações genômicas, exposições ambientais, hábitos de vida, comorbidades. Os biomarcadores diagnósticos e de desfecho terapêutico serão oriundos de plataformas ômicas (genômica, transcriptômica, proteômica, metabolômica, e outras) e serão analisados sob a perspectiva de redes complexas, nas quais as funções e disfunções biológicas estão associadas a processos temporais e espaciais que envolvem um grande número de componentes que interagem entre si e com as estruturas do corpo no nível molecular. A MP prevê protocolos com o emprego de softwares específicos para avaliação de minúcias nas imagens obtidas por métodos computadorizados, aumentando a capacidade diagnóstica dos exames de imagem. Entretanto, os dados clínicos e epidemiológicos serão sempre fundamentais. Como resultados da abordagem estratificada da MP, pode-se esperar a identificação prévia dos "respondedores" potenciais aos tratamentos, a descoberta de novos alvos terapêuticos e ações preventivas especificamente direcionadas.

É fácil imaginar que a quantidade de dados a serem analisados quando a MP estiver inserida na prática médica cotidiana será astronômica. Nesse cenário, a bioinformática $(\mathrm{BI})$ e a inteligência artificial (IA) serão instrumentos fundamentais na tomada de decisões. Serão necessários sistemas capazes de integrar o emaranhado de processos e apontar o teste diagnóstico, o(s) alvo(s) do tratamento e o(s) agente(s) terapêutico(s) adequado(s), levando em consideração, inclusive, a farmacogenética.

Dentre as inúmeras engrenagens associadas à MP que deverão ser reformuladas, encontra-se o sistema de atendimento à Saúde. Numa realidade em que os recursos são insuficientes e mal utilizados, em que as condições sanitárias, habitacionais, educacionais e políticas são desastrosas, a MP pode parecer utópica. Nela, alguns novos instrumentos, como os descritos abaixo, estarão diretamente ligados às práticas médicas.

\section{Microbioma}

Com a incorporação de tecnologia ômica, o estudo do microbioma (microbiômica) avançará permitindo, entre outros, descrever o gradiente entre "eubiose" e "disbiose", identificando a relevância nas diferenças de tamanho de cada população de microrganismos em cada microbiota, criando um "indicador de disbiose". Certamente, o avanço no conhecimento nessa área representará um impulso na MP, e o tratamento personalizado levará em consideração a maneira como o microbioma de cada pessoa participa dos mecanismos patogênicos em questão e interfere com 
o tratamento. O conhecimento atual sobre o papel do microbioma no funcionamento de sistemas vitais para o homem deixam claro que sua modulação será um instrumento importante no tratamento da asma. Mesmo que ainda sem bases sólidas, já estamos presenciando o emprego de prebióticos, probióticos, simbióticos e antibióticos no tratamento de uma diversidade de disfunções e doenças.

\section{Plataformas ômicas}

O termo "Ciências ômicas" refere-se ao uso de tecnologia refinada para identificar moléculas importantes nos processos biológicos. Inicialmente, o eixo central das investigações ômicas seguia o processo do DNA (genômica) gerar o RNA, que, através dos processos de transcrição e translação (transcriptômica), forma proteínas (proteômica) e metabólitos (metabolômica). Posteriormente, outras "ômicas" (epigenômica, microbiômica e exposômica) foram inseridas nas linhas de investigação, formando a Plataforma ômica (PO). A análise dos produtos em todas as fases desse eixo permite identificar processos patológicos e alvos terapêuticos, bem como seus respectivos biomarcadores ${ }^{51}$. Esses últimos - moléculas ou sequências genéticas que permitam identificar o processo patológico, o alvo terapêutico e prever a resposta ao tratamento - estão entre os principais objetivos da análise ômica. Outro objetivo importante é identificar a associação entre fenótipos e "mecanismos tratáveis" para orientar o desenvolvimento de agentes terapêuticos ${ }^{52}$. Dada a enormidade de dados a serem analisados e a complexidade dos métodos analíticos, a BI, a IA e métodos estatísticos sofisticados são fundamentais. Nessa tecnologia, ainda cara e realizada em poucos lugares, as redes biológicas são investigadas buscando significância estatística nas mudanças em suas concentrações e suas interações em múltiplos níveis ${ }^{53,54}$.

\section{Sequenciamento genômico}

O principal objetivo dos GWAS e da Medicina Genômica é traduzir as variantes genéticas identificadas para a clínica, ajudando a predição, o diagnóstico e o tratamento. O número de genomas humanos analisados superará centenas de milhares nos próximos anos, tornando difícil imaginar a escala de bioinformática necessária para analisar todo o potencial de informações contidas nos blocos de dados. A integração de novas tecnologias, como fe- notipagem reversa usando biomarcadores genéticos para definir endotipos moleculares ${ }^{55}$, às medidas multiômicas e ao uso de inteligência artificial e outros instrumentos da informática vem desvendando interfaces entre genes e mecanismos patogênicos da asma. Para esse processo, foi desenvolvida uma nova área da biologia computacional denominada "Pan-genoma computacional", na qual o conjunto de sequências genômicas pode ser analisado em conjunto ou ser usado como referência ${ }^{56}$.

\section{MicroRNA}

Tradicionalmente, o RNA era visto como uma molécula passiva, um mero agente numa etapa intermediária de "leitura" dos genes na atividade celular. $\mathrm{Na}$ verdade, é um agente importante com múltiplas atividades, responsável por controlar a atividade do gene. Sabe-se, hoje, que o RNA dispõe de recursos para editar o RNAm codificado por um gene e mudar radicalmente a função da proteína resultante. Essa capacidade de modificar o produto final é característica dos microRNAs (miRNA). Eles atuam na etapa pós-transcrição do RNAm desempenhando papel crucial na regulação de diversos processos biológicos, como sinalização celular, desenvolvimento de tecidos e órgãos, funções inatas e proliferação das células do sistema imune em resposta a estímulos patogênicos, entre outras funções ${ }^{57}$. Há duas classes de miRNA: intra e extracelulares. Os primeiros têm padrões específicos de expressão em doenças, o que os torna excelentes biomarcadores diagnósticos e prognósticos potenciais. Os segundos, circulam dentro de vesículas extracelulares (exossomos, microvesículas e corpos apoptóticos). Dessa forma, podem ser transferidos entre diferentes células e controlar seu funcionamento 58,59 . Seu valor potencial no tratamento de doenças respiratórias, dentre elas a asma ${ }^{60,61}$, talvez promovendo o retorno ao comportamento normal das células alvo, vem estimulando estudos 62,63 .

\section{Biomarcadores}

A MP está apoiada na presença de biomarcadores validados que permitam estratificar cada pessoa de acordo com fatores como o risco da doença provável, prognóstico e resposta terapêutica. Diversas tecnologias vêm sendo avaliadas com o objetivo de permitir análise integrada do grande número de moléculas envolvidas nos diferentes níveis dos 
sistemas biológicos e identificar/ranquear biomarcadores potenciais. Porém, o uso ainda restrito das PO em poucos locais faz com que os estudos para validá-los ainda tenham poder estatístico reduzido e pouca reprodutibilidade.

\section{Terapia alvo}

A identificação precisa do alvo do agente terapêutico é fundamental no seu desenvolvimento. Nesse contexto, a resposta ao tratamento também está ligada à variação genética que permeia a configuração do endotipo responsável pelo distúrbio alvo. Nesse processo complexo de desenvolvimento do agente terapêutico específico para seu alvo, são identificadas as biomoléculas alvo, definida a relação entre um gen e o alvo terapêutico, e estabelecido o mecanismo de ação do agente terapêutico ${ }^{64}$.

\section{Nanotecnologia}

Técnica envolvendo a manipulação e inserção de átomos e moléculas medindo de 0,1 a $100 \mathrm{~nm}$ potencialmente úteis em abordagens terapêuticas mediante a manufatura de estruturas desenhadas especialmente para carrear o agente para a célula alvo ${ }^{65}$. Seguindo o exemplo da natureza, que utiliza as vesículas extracelulares contendo miRNA como instrumento de modulação de funções celulares, pode-se imaginar que a utilização de nanomateriais com uma parede externa especificamente desenhada para ser "fagocitada" pela célula alvo e que, uma vez dentro dela, liberaria agentes (fármacos, moduladores genéticos, miRNA, p. ex.) capazes de fazer com que o objetivo terapêutico fosse alcançado ${ }^{54}$. Por exemplo, no tratamento de um asmático, a administração inalatória de uma nanopartícula específica para ser englobada por um eosinófilo ou um mastócito ativados promovendo a interrupção da produção aumentada de citocinas ou mediadores inflamatórios envolvidos nos processos patogenéticos da asma. $O$ mesmo pode ser pensado para as células epiteliais e musculares lisas dos brônquios, ou qualquer outra célula do trato respiratório. Esse racional vem sendo objeto de estudos promissores na área das doenças respiratórias crônicas ${ }^{66,67}$. Num futuro próximo, nanocarregadores multifuncionais, com alvos em ligantes celulares específicos, e combinações da nanotecnologia com terapia genética e células tronco, serão empregados, aumentando a eficiência terapêutica e reduzindo a toxicidade de agentes terapêuticos atuais e futuros.

\section{Farmacogenética e farmacogenômica}

A farmacogenética e a farmacogenômica estudam a variabilidade interindividual na resposta terapêutica aos fármacos. Essa variação, que vai desde a falta de resposta até as reações adversas, tem por base as diferenças genéticas entre as pessoas, embora alguns fatores ambientais também possam contribuir para os efeitos adversos ${ }^{68}$. O termo farmacogenética foi usado, inicialmente, em 1959, significando "o estudo de fatores genéticos que influenciam a resposta a fármacos". Com o progresso dos estudos genéticos, que tornou possível avaliar todo o genoma, o termo foi modificado para farmacogenômica, envolvendo todo o espectro de genes no genoma humano ${ }^{69}$. Visando estudar a farmacogenômica na asma infantil, foi criado um consórcio internacional em 2013, cujo objetivo é identificar marcadores farmacogenômicos através da metanálise de GWAS e desenvolver algoritmos para guiar o tratamento da asma ${ }^{70}$.

O progresso do conhecimento científico sobre os mecanismos patogênicos envolvidos nas diversas formas clínicas da asma vem deixando cada vez mais clara a complexidade da participação de fatores genéticos e microbiômicos. Os resultados das interações genoma-microbioma são agentes importantes nos processos patogênicos presentes no asmático. Ainda estamos na fase de identificar diferenças: diferenças na estrutura do DNA dos asmáticos, diferenças epigenéticas na população de asmáticos, diferenças na composição e diversidade da microbiota pulmonar. Ainda precisamos aprender como interpretar essas diferenças. Num contexto como o da asma, uma disfunção respiratória cuja apresentação clínica e abordagem terapêutica variam ao longo do tempo num mesmo indivíduo, provavelmente as diferenças genômicas e microbiômicas identificadas não geram expressões clínicas iguais todo o tempo.

Costuma-se dizer que a pergunta é mais importante que a resposta, porque é a pergunta que sintetiza a necessidade do "saber". Será que a variação clínica da asma sem alterações de fatores ambientais estaria relacionada a mudanças pontuais no microbioma? Provavelmente não, a não ser que todas as variações ocorressem quando houvesse uso de antibióticos, mudanças na dieta ou na presença de outros moduladores do microbioma. Será que se deve a alterações epigenéticas? Provavelmente não, já que, nesse caso de mudança de padrões fenotípicos não haveria recorrência de padrões anteriores. Estudos da celularidade do escarro mostram mudanças ao longo do tempo, demonstrando, 
indiretamente, alterações no mecanismo patogênico independentes de fatores externos. Como justificar essas alterações utilizando o conhecimento atual sobre epigenoma e microbioma? Sabemos que o genoma modula o microbioma e vice-versa. Sabemos, também, que ambos são modulados pelo ambiente externo, estilo de vida, uso de medicamentos, e outros fatores. Entretanto, não descobrimos, ainda, de que forma essas modulações geram produtos (endotipos e formas clínicas) diferentes em momentos diferentes. O desconhecido ainda supera o conhecido, atiçando nossa curiosidade, induzindo pesquisas.

\section{Conclusão}

As respostas às questões como as citadas acima trarão melhores perspectivas para o tratamento dos asmáticos, particularmente daqueles portadores de formas graves, para os quais os recursos terapêuticos atuais são insuficientes. Possivelmente, em algum momento futuro (quanto mais próximo, melhor) a classificação e o tratamento individualizado do asmático será resultante da integração de dados clínicos, fenotípicos, endotípicos, genômicos, epigenômicos, transcriptômicos, proteômicos, metabolômicos, microbiômicos, imunômicos, ambientais, dietéticos e do estilo de vida. Os objetivos do tratamento não mais serão anti-inflamação, broncodilatação, bloquear liberação de mediadores pelos mastócitos ou reduzir o número de eosinófilos; o objetivo terapêutico será reverter ou antagonizar os mecanismos responsáveis pelo(s) endotipo(s) molecular(es) envolvido(s). Nesse momento, através da Nanotecnologia, será colocar fármacos e microRNAs selecionados nas células alvo do trato respiratório, promovendo seu retorno ao funcionamento normal.

\section{Referências}

1. Scherzer R, Grayson MH. Heterogeneity and the origins of Asthma. Ann Allergy Asthma Immunol. 2018;121(4):400-5.

2. Tyler SR, Bunyavanich S. Leveraging-omics for asthma endotyping. J Allergy Clin Immunol. 2019;144(1):13-23.

3. Wang L, Feng M, Qiuwen Li, Qiu C, Chen R. Advances in nanotechnology and asthma. Ann Transl Med 2019;7(8):180.

4. Agache IO. From phenotypes to endotype to asthma treatment. Curr Opin Allergy Clin Immunol. 2013;13(3):249-56.

5. Isidoro-García M, Sánchez-Martín A, García-Sánchez A, Sanz C, García-Berrocal B, Dávila I. Pharmacogenetics and the treatment of asthma. Pharmacogenomics. 2017;18(13):1271-80.

6. Agache I, Akdis CA.Precision medicine and phenotypes, endotypes, genotypes, regiotypes, and theratypes of allergic diseases. J Clin Invest. 2019;129(4):1493-503.

7. Agache I, Rogozea L. Asthma biomarkers: do they bring precision medicine closer to the clinic? Allergy Asthma Immunol Res. 2017;9(6):466-76.
8. Thomsen SF, van der Sluis S, Kyvik KO, Skytthe A, Backer V. Estimates of asthma heritability in a large twin sample. Clin Exp Allergy. 2010;40(7):1054-61.

9. Moffatt MF, Gut IG, Demenais F, Strachan DP, Bouzigon E, Heath $\mathrm{S}$, et al. A large-scale, consortium-based genomewide association study of asthma. N Engl J Med. 2010;363(13):1211-21.

10. Manolio TA, Collins FS, Cox NJ, Goldstein DB, Hindorff LA, Hunter DJ, et al. Finding the missing heritability of complex diseases. Nature. 2009 Oct 8;461(7265):747-53.

11. Martinez FD, Vercelli D. Asthma. Lancet. 2013;382:1360-72.

12. von Mutius $E$, Vercelli D. Farm living: effects on childhood asthma and allergy. Nat Rev Immunol. 2010;10:861-8.

13. Ober C, VercelliD. Gene-environment interactions in human disease: nuisance or opportunity? Trends Genet. 2011;27:107-15.

14. Riggs AD, Porter TN. Overview of Epigenetic Mechanisms. Cold Spring Harbor Monograph Archive. 1996;32:29-45.

15. Zhang H, Tong X, Holloway JW, Rezwan FI, Lockett GA, Patil V, et al. The interplay of DNA methylation over time with Th2 pathway genetic variants on asthma risk and temporal asthma transition. Clin Epigenetics. 2014;6(1):8.

16. Seumois G, Chavez L, Gerasimova A, Lienhard M, Omran N, Kalinke $L$, et al. Epigenomic analysis of primary human $T$ cells reveals enhancers associated with $\mathrm{TH} 2$ memory cell differentiation and asthma susceptibility. Nat Immunol. 2014;15(8):777-88.

17. Gerasimova A, Chavez L, Li B, Seumois G, Greenbaum J, Rao $A$, et al. Predicting cell types and genetic variations contributing to disease by combining GWAS and epigenetic data. PLoS One. 2013;8(1):e54359.

18. Liang L, Willis-Owen SAG, Laprise C, Wong KCC, Davies GA, Hudson TJ, etal. An epigenome-wide association study of total serum immunoglobulin E concentration. Nature. 2015;520(7549):670-4.

19. Brook PO, Perry MM, Adcock IM, Durham AL. Epigenome-modifying tools in asthma. Epigenomics. 2015;7(6):1017-32.

20. Behjat S, Tarpey OS. What is generation sequencing? Arch Dis Child Educ Pract Ed. 2013;98:236-8.

21. Moffatt MF, Gut IG, Demenais F, Strachan DP, Bouzigon E, Heath $\mathrm{S}$, et al. A large-scale, consortium-based genomewide association study of asthma. N Engl J Med. 2010;363(13):1211-21.

22. Galanter JM, Gignoux CR, Torgerson DG, Roth LA, Eng C, Oh SS, et al. Genome-wide association study and admixture mapping identify different asthma-associated loci in Latinos: the Genes-environments \& Admixture in Latino Americans study. J Allergy Clin Immunol. 2014;134(2):295-305.

23. Almoguera B, Vazquez L, Mentch F, Connolly J, Pacheco JA, Sundaresan AS, et al. Identification of Four Novel Loci in Asthma in European American and African American Populations. Am J Respir Crit Care Med. 2017;195(4):456-63.

24. Nieuwenhuis MA, Siedlinski M, van den Berge M, Granell R, Li X, Niens $M$, et al. Combining genomewide association study and lung eQTL analysis provides evidence for novel genes associated with asthma. Allergy. 2016;71(12):1712-20.

25. Slager RE, Hawkins GA, Li X, Postma DS, Meyers DA, Bleecker ER. Genetics of asthma susceptibility and severity. Clin Chest Med. 2012;33(3):431-43.

26. Schoettler N, Rodríguez E, Weidinger S, Ober C. Advances in asthma and allergic disease genetics: Is bigger always better? J Allergy Clin Immunol. 2019;144(6):1495-506.

27. García-Menaya JM, Cordobés-Durán C, García-Martín E, Agúndez JAG. Pharmacogenetic Factors affecting asthma treatment response. potential implications for drug therapy. Front Pharmacol. 2019;10:520.

28. Tantisira KG, Lake S, Silverman ES, Palmer LJ, Lazarus R, Silverman EK, et al. Corticosteroid pharmacogenetics: association of sequence variants in CRHR1 with improved lung function in asthmatics treated with inhaled corticosteroids. Hum Mol Genet. 2004;13(13):1353-9.

29. Tantisira KG, Lasky-Su J, Harada M, Murphy A, Litonjua AA, Himes BE, et al. Genomewide association between GLCCI1 and response to glucocorticoid therapy in asthma. $\mathrm{N}$ Engl $\mathrm{J}$ Med. 2011;365(13):1173-83. 
30. Hawkins GA, Lazarus R, Smith RS, Tantisira KG, Meyers DA, Peters SP, et al. The glucocorticoid receptor heterocomplex gene STIP1 is associated with improved lung function in asthmatic subjects treated with inhaled corticosteroids. J Allergy Clin Immunol. 2009;123(6):1376-83.e7.

31. Bleecker ER, Postma DS, Lawrance RM, Meyers DA, Ambrose $\mathrm{HJ}$, Goldman M. Effect of ADRB2 polymorphisms on response to longacting beta2-agonist therapy: a pharmacogenetic analysis of two randomised studies. Lancet. 2007 Dec 22;370(9605):2118-25.

32. Israel E, Drazen JM, Liggett SB, Boushey HA, Cherniack RM, Chinchilli VM, et al. The effect of polymorphisms of the beta(2)adrenergic receptor on the response to regular use of albuterol in asthma. Am J Respir Crit Care Med. 2000;162(1):75-80.

33. WechslerME, Kunselman SJ, ChinchilliVM, BleeckerE, Boushey HA, CalhounWJ, et al. Effect of beta2-adrenergic receptor polymorphism on response to longacting beta2 agonist in asthma (LARGE trial): a genotype-stratified, randomised, placebo-controlled, crossover trial. Lancet. 2009;374(9703):1754-64.

34. Petersen C, Round JL. Defining dysbiosis and its influence on host immunity and disease. Cell Microbiol. 2014;16:1024-33.

35. The Human Microbiome Project Consortium. Structure, function and diversity of the healthy human microbiome. Nature. 2012;486:207-14.

36. Luca F, Kupfer SS, Knights D, Khoruts A, Blekhman R. Functional Genomics of Host-Microbiome Interactions in Humans. Trends Genet. 2018;34(1):30-40.

37. Budden KF, Shukla SD, Rehman SF, Bowerman KL, Keely S, Hugenholtz $\mathrm{P}$, et al. Functional effects of the microbiota in chronic respiratory disease. Lancet Respir Med. 2019;7(10):907-20.

38. Kundu P, Blacher E, Elinav E, Pettersson S. Our Gut Microbiome: The Evolving Inner Self. Cell. 2017;171(7):1481-93.

39. Nichols RG, Peters JM, Patterson AD. Interplay between the host, the human microbiome and drug metabolism. Human Genomics. 2019;13(1):27-37.

40. Sokolowska M, Frei R, Lunjani N, Akdis CA, O'Mahony L. Microbiome and asthma. Asthma Res Pract. 2018;4:1.

41. Sullivan A, Hunt E, MacSharry J, Murphy DM. 'The Microbiome and the Pathophysiology of Asthma'. Respir Res. 2016;17(1):163.

42. Huang YJ, Nelson CE, Brodie EL, Desantis TZ, Baek MS, Liu J, et al. Airway microbiota and bronchial hyperresponsiveness in patients with suboptimally controlled asthma. J Allergy Clin Immunol. 2011;127(2):372-381.e1-3.

43. Singanayagam A, Ritchie Al, Johnston SL. Role of microbiome in the pathophysiology and disease course of Asthma. Curr Opin Pulm Med. 2017;23(1):41-7.

44. Denner DR, Sangwan N, Becker JB, Hogarth DK, Oldham J, Castillo $\mathrm{J}$, et al. Corticosteroid therapy and airflow obstruction influence the bronchial microbiome, which is distinct from that of bronchoalveolar lavage in asthmatic airways. J Allergy Clin Immunol. 2016;137(5):1398-1405.e3.

45. Wong EH, Porter JD, Edwards MR, Johnston SL. The role of macrolides in asthma: current evidence and future directions. Lancet Respir Med. 2014;2(8):657-70.

46. Simpson JL, Daly J, Baines KJ, Yang IA, Upham JW, Reynolds PN, et al. Airway dysbiosis: Haemophilus influenzae and Tropheryma in poorly controlled asthma. Eur Respir J. 2016;47(3):792-800.

47. Orivuori L, Mustonen K, de Goffau MC, Hakala S, Paasela M, Roduit $\mathrm{C}$, et al. High level of fecal calprotectin at age 2 months as a marker of intestinal inflammation predicts atopic dermatitis and asthma by age 6. Clin Exp Allergy. 2015;45(5):928-39.

48. Kalliomäki M, Kirjavainen P, Eerola E, Kero P, Salminen S, Isolauri E. Distinct patterns of neonatal gut microflora in infants in whom atopy was and was not developing. J Allergy Clin Immunol. 2001;107(1):129-34.

49. van Nimwegen FA, Penders J, Stobberingh EE, Postma DS, Koppelman $\mathrm{GH}$, Kerkhof $\mathrm{M}$, et al. Mode and place of delivery, gastrointestinal microbiota, and their influence on asthma and atopy. J Allergy Clin Immunol. 2011;128(5):948-55.e1-3.
50. Hevia A, Milani C, López P, Donado CD, Cuervo A, González S, et al. Allergic Patients with Long-Term Asthma Display Low Levels of Bifidobacterium adolescentis. PLoS One. 2016;11(2):e0147809.

51. Virkud YV, Kelly RS, Wood C, Lasky-Su JA. The nuts and bolts of omics for the clinical allergist. Ann Allergy Asthma Immunol. 2019;123(6):558-63.

52. Colas L, Hassoun D, Magnan A. Needs for systems approaches to better treat individuals with severe Asthma: predicting phenotypes and responses to treatments. Frontiers in Medicine. 2020;7(98):1-18.

53. Wang M, Yu G, Ressom HW. Integrative Analysis of Proteomic, Glycomic, and Metabolomic Data for Biomarker Discovery. IEEE J Biomed Health Inform. 2016;20(5):1225-31.

54. Butte AJ, Kohane IS. Mutual information relevance networks: functional genomic clustering using pairwise entropy measurements. Pac Symp Biocomput. 2000:418-29.

55. Dahl A, Cai N, Ko A, Laakso M, Pajukanta P, Flint J, et al. Reverse GWAS: Using genetics to identify and model phenotypic subtypes. PLoS Genet. 2019;15(4):e1008009.

56. Computational Pan-Genomics Consortium. Computational pangenomics: status, promises and challenges. Brief Bioinform. 2018;19(1):118-35.

57. Kingsley SM, Bhat BV. Role of microRNAs in sepsis. Inflamm Res. 2017;66:553-69.

58. Harris KS, Zhang Z, McManus MT, Harfe BD, Sun X. Dicer function is essential for lung epithelium morphogenesis. Proc Natl Acad Sci U S A. 2006;103(7):2208-13.

59. Zhang J, Li S, Li L, Li M, Guo C, Yao J, et al. Exosome and exosomal microRNA: trafficking, sorting, and function. Genomics Proteomics Bioinformatics. 2015;13(1):17-24.

60. Tay HL, Plank M, Collison A, Mattes J, Kumar RK, Foster PS. MicroRNA: potential biomarkers and therapeutic targets for allergic asthma? Ann Med. 2014;46:633-9.

61. Mortaz E, Alipoor SD, Varahram M, Jamaati H, Garssen J, Mumby SE, et al. Exosomes in Severe Asthma: Update in Their Roles and Potential in Therapy. Biomed Res Int. 2018;2018:2862187.

62. Gon Y, Shimizu T, Mizumura K, Maruoka S, Hikichi M. Molecular techniques for respiratory diseases: MicroRNA and extracellular vesicles. Respirology. 2020;25(2):149-60.

63. Chen J, Hu C, Pan P. Extracellular Vesicle MicroRNA Transfer in Lung Diseases. Front Physiol. 2017;8:1028.

64. Santos R, Ursu O, Gaulton A, Bento AP, Donadi RS, Bologa CG, et al. A comprehensive map of molecular drug targets. Nat Rev Drug Discov. 2017;16(1):19-34.

65. Passi M, Shahid S, Chockalingam S, Sundar IK, Packirisamy G. Conventional and Nanotechnology Based Approaches to Combat Chronic Obstructive Pulmonary Disease: Implications for Chronic Airway Diseases. Int J Nanomedicine. 2020;15:3803-26.

66. Wang L, Feng M, Li Q, Qiu C, Chen R. Advances in nanotechnology and asthma. Ann Transl Med. 2019 Apr;7(8):180.

67. Barnes PJ.Targeting cytokines to treat asthma and chronic obstructive pulmonary disease. Nat Rev Immunol. 2018;18:454-66.

68. Schimke RN. Drugs and heredity. Pharmacogenetics - the study of heritable variations in drug response. J Kans Med Soc. 1969;70(3):146-50.

69. Meyer UA. Pharmacogenetics - five decades of therapeutic lessons from genetic diversity. Nat Rev Genet. 2004; 5(9):669-76.

70. Farzan N, Vijverberg SJ, Andiappan AK, Arianto L, Berce $\mathrm{V}$, Blanca-López $\mathrm{N}$, et al. Rationale and design of the multiethnic Pharmacogenomics in Childhood Asthma consortium. Pharmacogenomics. 2017;18(10):931-43.

Não foram declarados conflitos de interesse associados à publicação deste artigo.

Correspondência:

Hisbello da Silva Campos

E-mail: hisbello@globo.com 